\title{
Three-Dimensional Physical Simulation of Heavy Oil Exploitation by Hot Solvent Injection
}

\author{
Yang Liu, ${ }^{1}$ Rui Han $\mathbb{D}^{2},{ }^{2}$ Songyan Li $\mathbb{D}^{3}$ and Ishaq Ahmad ${ }^{2}$ \\ ${ }^{1}$ Research Institute of Petroleum Exploration and Development, PetroChina, Beijing 100083, China \\ ${ }^{2}$ School of Petroleum Engineering, China University of Petroleum (East China), Qingdao 266580, China \\ ${ }^{3}$ Key Laboratory of Unconventional Oil \& Gas Development (China University of Petroleum (East China)), Ministry of Education, \\ Qingdao 266580, China
}

Correspondence should be addressed to Songyan Li; lsyupc@163.com

Received 20 August 2021; Accepted 22 November 2021; Published 4 January 2022

Academic Editor: Guangquan Li

Copyright (c) 2022 Yang Liu et al. This is an open access article distributed under the Creative Commons Attribution License, which permits unrestricted use, distribution, and reproduction in any medium, provided the original work is properly cited.

To improve the thermal effects of solvents on heavy oil reservoirs and realize the combined action of multiple flooding mechanisms, such as solvent heating and extraction, without steam mixing, based on the M Block heavy oil reservoir in Canada, three sets of comparative hot solvent-assisted gravity drainage experiments under different temperatures and pressures were carried out through an indoor three-dimensional (3D) physical simulation device. The development characteristics of the solvent chamber in the hot solvent-assisted gravity drainage technology were studied under different pressures and temperatures, and the recovery factor, cumulative oil exchange rate, and solvent retention rate were analyzed. The results showed that due to the effect of gravity differentiation, the development morphology of the solvent chamber could be divided into three stages: rapid ascent, lateral expansion, and slow descent. When the temperature was constant, the reservoir pressure decreased, the recovery rate increased, the cumulative oil exchange rate increased, and the solvent retention rate decreased; when the pressure was constant, the temperature increased, the viscosity of heavy oil decreased, the recovery rate increased, the cumulative oil exchange rate increased, and the solvent retention rate was low. Additionally, the study also showed that for hot solvents in different phases, the use of hot solvent vapor not only required less injected solvent but also exhibited a high oil production rate, which shortened production time and reduced energy consumption. Moreover, the oil recovery rate was higher than $60 \%$, the solvent retention rate was lower than $10 \%$, and the cumulative oil exchange rate was higher than $3 \mathrm{t} / \mathrm{t}$, which constituted better economic benefits and provided a reliable theoretical basis for onsite oilfield applications.

\section{Introduction}

Due to the impact of the energy crisis, the exploitation of heavy oil and other unconventional oils and gases has attracted increasing attention, and the exploitation of heavy oils has also been constantly evolving [1-4]. Steam-assisted gravity drainage (SAGD) is a thermal recovery technology that emerged in the 1980s for the efficient extraction of heavy oil [5]. However, SAGD not only has problems such as low heat utilization efficiency and limited mining methods but also has problems including the treatment of water produced, the consumption of large amounts of freshwater resources, and possible damage to the formation caused by clay expansion. In addition, a large amount of flue gas is generated during the development of SAGD, which is inconsistent with development concepts based on energy savings, emission reduction, and environmental protection at home and abroad [6-9].

To solve this problem, Butler and Mokrys [10] proposed a solvent extraction technology (VAPEX) in 1989, which uses solvent instead of steam. It adopts the same well pattern structure as SAGD with one upper and double horizontal lower wells. It reduces the viscosity of heavy oil by injecting normal temperature gaseous light hydrocarbon solvents from the upper injection wells to form diluent oil flowing out of the lower production wells. Therefore, this process is generally considered to be a cold-drying (i.e., nonthermal) process. VAPEX has two important mechanisms of action 
[11]. On the one hand, the solvent extracts and dissolves the thick oil and reduces the viscosity. On the other hand, there is mass transfer between the solvent and the heavy oil. Moreover, Das and Butler [12] also pointed out that to avoid formation damage caused by the precipitation of asphaltenes, the VAPEX process must be operated under noncondensing (i.e., dew point) conditions.

Many scholars have studied the type of solvent injected, operating pressure, temperature, injection rate, injection method, model permeability, and porosity in VAPEX technology [13-21]. They believe that conventional VAPEX is a feasible processing technology, but due to the high price of solvents and poor economic efficiency, it cannot be widely used commercially. As a result, more VAPEX-derived processes began to appear, such as the N-Solv process, the expanded solvent SAGD process, the cone solvent SAGD process, the steam alternate solvent process, and the hot solvent process [22-25].

E. Nenniger and J. Nenniger [26] proposed the N-Solv process, which involves heating the solvent into vapor and injecting it into the oil reservoir. The solvent conducts the latent heat of condensation into the reservoir and dissolves the crude oil, which reduces the viscosity of the produced heavy oil and bitumen, improves its fluidity, and causes it to flow into the production well under the action of gravity. James [27] believes that the higher the temperature is, the greater the saturation pressure. The heated hot solvent provides higher injection pressure to the reservoir, which provides the possibility of solvent injection for deep-bed high-pressure reservoirs.

The warm solvent process is a steam-free mixing method similar to N-Solv. The only difference is that the solvent is heated to form a superheated steam and injected into the formation. The superheated solvent vapor condenses and releases heat at the interface between the solvent and the oil and mixes with the crude oil [28]. Rezaei [29, 30] researched warm solvent extraction of Cold Lake bitumen and Lloydminster heavy oil by heating n-pentane $\left(36^{\circ} \mathrm{C}\right.$, $43^{\circ} \mathrm{C}$, and $50^{\circ} \mathrm{C}$ ). The results showed that under the effect of solvent overheating, the solvent concentration in the output oil was significantly reduced, and the solvent-oil ratio was significantly reduced. The residual oil saturation in the porous media of the two oil samples increased slightly with increasing solvent vapor temperature; moreover, with increasing solvent temperature, the output content of asphaltene also increased. Frauenfeld et al. [31] compared this heating method with that of conventional VAPEX and pointed out that the purpose of heating is to establish communication between the injection well and the production well more quickly and further reduce the viscosity of the crude oil near the well.

The heavy oil in a low-temperature reservoir is very sensitive to temperature. Although the solvent in the above study was overheated, its temperature was still low $\left(<80^{\circ} \mathrm{C}\right)$. When it was injected into the reservoir, a large amount of heat would be lost in the wellbore, resulting in a little impact on the temperature of the heavy oil in the reservoir. To improve the thermal impact of solvents on heavy oil reservoirs and realize the combined action of multiple flood- ing mechanisms, such as solvent heating and extraction, without steam mixing, this paper takes the M Block heavy oil reservoir in Canada as the target block and conducts three sets of $3 \mathrm{D}$ indoor physical simulation experiments at different temperatures and pressures when the solvent is heated to high temperature and superheated. The development of the temperature field of the superheated solvent was compared, and the effects of temperature and pressure on the oil production rate, recovery factor, cumulative oil exchange rate, and solvent retention rate of the injected superheated solvent vapor were studied.

\section{Experimental Section}

2.1. Materials. The oil used in the experiment was taken from the M Block heavy oil reservoir, degassed and dehydrated by a dehydrator. The original heavy oil was mixed with kerosene to conduct $3 \mathrm{D}$ indoor physical simulation experiments in order to fulfill the similarity criterion. The relationship between viscosity and temperature was measured between $20^{\circ} \mathrm{C}$ and $110^{\circ} \mathrm{C}$ by a rheometer (Anton Paar, MCR302, Austria), as shown in Figure 1. The viscosity of crude oil decreased with increasing temperature, and the viscosity of crude oil was $1024 \mathrm{mPa} \cdot \mathrm{s}$ at $50^{\circ} \mathrm{C}$. Quartz sand (40-70 mesh) was used to fill the physical model, and the water was deionized water provided by a UPT ultrapure water device (Sichuan Youpu Ultrapure Technology Co., LTD., UPT-I-10 T, China). The experimental solvent was n-pentane with a purity of more than 98\% (Xilong Chemical Co., Ltd.).

2.2. Apparatus. The high-temperature and high-pressure $3 \mathrm{D}$ reservoir simulation system consisted of four parts: an injection system, a 3D model, a production system, and a control recording system. The experimental flowchart is shown in Figure 2. The injection system included two ISCO highprecision plunger pumps (100DX from Teledyne ISCO Company, Teledyne Co., Ltd., Thousand Oaks, CA, USA; flow accuracy of $\pm 0.25 \mu \mathrm{l} / \mathrm{min}$, and pressure accuracy of $\pm 0.5 \%$ ), an oil bath, a temperature sensor (PR-13 from OMEGA Engineering, USA, with a temperature range of $500^{\circ} \mathrm{C}$ and temperature accuracy of $\pm 0.2^{\circ} \mathrm{C}$ ), a one-way valve, and three intermediate containers. The $3 \mathrm{D}$ model was a rectangular parallelepiped structure with an internal size of $300 \times 300 \times 200 \mathrm{~mm}$. The highest experimental temperature was $300^{\circ} \mathrm{C}$, and the highest experimental pressure was $8 \mathrm{MPa}$. There were 40 pressure measuring points (pressure accuracy of $\pm 1 \mathrm{kPa}$ ) and 64 temperature measuring points (temperature accuracy of $\pm 0.2^{\circ} \mathrm{C}$ ) on the model. The output system included a control valve, back pressure valve, beaker, measuring cylinder, and high-precision electronic scale. The control recording system included a computer, and temperature and pressure sensors.

2.3. Similarity Criterion. Because VAPEX adopts the same well pattern structure as SAGD, the 3D physical experiment parameters were designed according to the similarity criterion of SAGD (1-3) and the geological and production 




FIGURE 1: Relationship between viscosity and temperature of experimental oil.

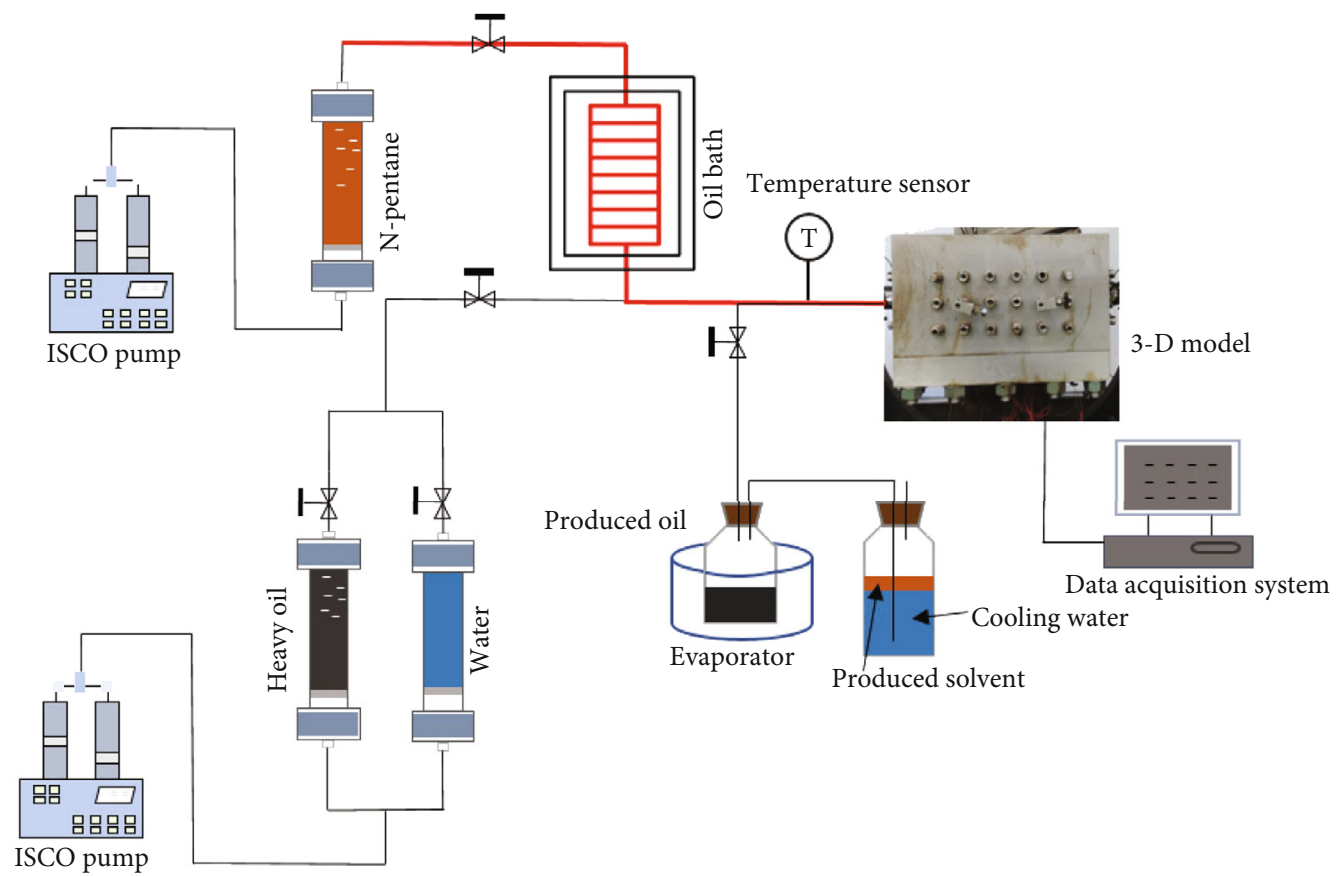

FIgURE 2: Flowchart of the 3D physical experiment of hot solvent mining oil sand technology.

parameters of the $\mathrm{M}$ Block reservoir in Canada. The results are shown in Table 1.

Firstly, the criterion number $B_{3}$ is a dimensionless parameter of SAGD, which is used to realize the conversion between model and prototype permeability, as shown in equation (1):

$$
B_{3}=\sqrt{\frac{K g h \rho_{o}}{\alpha \phi S_{o} m \mu_{o}}}
$$

Secondly, the criterion number $F_{o}$ represents the dimensionless production time of unsteady heat conduction in the SAGD process, which is used to realize the conversion between prototype production time and model production time, as shown in equation (2):

$$
F_{o}=\frac{\alpha t}{h^{2}}
$$

Then, the physical meaning of the criterion number $q$ is the ratio of the amount of steam injection to the amount of 
TABLE 1: Fluid parameters of the reservoir and model geology.

\begin{tabular}{lcc}
\hline Physical property & Reservoir data & Model data \\
\hline Geometric size $(\mathrm{m})$ & $30 \times 30 \times 20$ & $0.3 \times 0.3 \times 0.2$ \\
Horizontal well length $(\mathrm{m})$ & 25 & 0.25 \\
Well spacing $(\mathrm{m})$ & 5 & 0.05 \\
Porosity $(\%)$ & 34 & 41.5 \\
Permeability $\left(10^{-3}{\left.\mu \mathrm{m}^{2}\right)}^{2}\right.$ & 2700 & 12850 \\
Initial oil saturation $(\%)$ & 80.5 & 90.85 \\
Oil viscosity at $50^{\circ} \mathrm{C}(\mathrm{mPa} \cdot \mathrm{s})$ & 15623 & 1024 \\
Oil density at $50^{\circ} \mathrm{C}\left(\mathrm{kg} \cdot \mathrm{m}^{-3}\right)$ & 1032 & 936 \\
Rate of steam injection $\left(\mathrm{t} \cdot \mathrm{d}^{-1}\right)$ & 1.35 & $0.018(20 \mathrm{ml} / \mathrm{min})$ \\
\hline
\end{tabular}

movable oil, which is used to realize the conversion of the steam injection rate between the model and the prototype, as shown in equation (3):

$$
q=\frac{i_{s} t}{\phi S_{o} \rho_{o} L^{3}}
$$

where $\rho_{o}$ is the oil density, $\mathrm{kg} / \mathrm{m}^{3} ; K$ is the permeability, $10^{-3} \mu \mathrm{m}^{2} ; \alpha$ is thermal diffusivity, $\mathrm{m}^{2} / \mathrm{s} ; \mu_{o}$ is the oil viscosity, $\mathrm{mPa} \cdot \mathrm{s} ; S_{o}$ is the mobile oil saturation; $\mathrm{g}$ is gravity acceleration, $\mathrm{m} / \mathrm{s}^{2} ; h$ is reservoir thickness, $\mathrm{m} ; m$ is the viscositytemperature index of heavy oil; $t$ is production time, $\mathrm{d} ; i_{s}$ is the rate of steam injection, $t / \mathrm{d} ; \varphi$ is the porosity; and $L$ is the horizontal well length, $\mathrm{m}$.

\subsection{Experimental Steps}

(1) The model was first installed on the support, and the bottom layer of the cover was placed according to the requirements of the experimental process. Second, the model simulation well and the model pressure measurement pipeline were installed, and the electric heating wire was wound on the simulation well

(2) The 3D model was filled with 40-70 mesh mixed quartz sand, the experimental sand was spread evenly, the thickness of the sand added each time was approximately 1-2 $\mathrm{mm}$, and this was continued until the model was filled. The model was vacuumed and saturated with water, and the volume of saturated water was recorded

(3) The model was heated to $50^{\circ} \mathrm{C}$, the crude oil was saturated at an injection rate of $5 \mathrm{ml} / \mathrm{min}$ after the temperature stabilized, the crude oil was stably and continuously flowed out at the output end, the volume of saturated oil was recorded, and the initial oil saturation level was calculated

(4) The injection-production well was heated by electric heating so that the temperature field between the two wells was connected and reached $100^{\circ} \mathrm{C}$. At the same time, the temperature of the oil bath was set to heat the solvent to a predetermined temperature
(5) The development of solvent injection in the simulation was started, and solvent was injected into the model at an injection speed of $20 \mathrm{ml} / \mathrm{min}$ (equivalent liquid)

(6) During the experiment, the temperature data collector automatically recorded the model temperature data and the oil production data was measured every 15 minutes. To evaluate the amount of solvent that was produced, it was collected and condensed, and its mass was measured. The experimental parameters are shown in Table 2

\section{Results and Discussion}

\subsection{Experiment 1}

3.1.1. Solvent Chamber. The temperature of the hot solvent vapor injected in Experiment 1 was $200^{\circ} \mathrm{C}$, and the backpressure was $2 \mathrm{MPa}$. According to the records of various temperature measurement points in the three-dimensional experimental model, the temperature fields of the interwell warm-up, early, middle, and end stages of Experiment 1 were drawn.

The injection well and the production well were preheated by electric heating, and the result is shown in Figure 3. The temperature between the injection well and the production well reached approximately $100^{\circ} \mathrm{C}$, and the crude oil between the wells was preheated well, which is beneficial for increasing the initial production rate of the reservoir and increasing the initial rate of oil production.

Figure 4 shows the temperature field produced during the early stage of hot solvent production in Experiment 1 . It can be seen from Figure 4(a) that with the continuous injection of hot solvent vapor, the hot solvent preferentially migrated to the top of the model under the effect of gravity, resulting in an elongated solvent temperature field. Further, Figure 4(b) shows that the hot solvent heated the heavy oil injected into the upper part of the well during the upward migration process. While the hot solvent dissolved and reduced the viscosity of the heavy oil, it also increased the temperature of the crude oil, reduced the viscosity of the heavy oil, and improved its fluidity.

When the injection well continued to inject hot solvent vapor, the solvent chamber gradually formed and developed, and the area of the high-temperature area increased, as shown in Figure 5. Due to the difference in densities between the hot solvent and the heavy oil, the hot solvent continuously moved upward along the solvent chamber. When the hot solvent overlapped the top of the model, the solvent chamber began to gradually expand laterally due to the limitation of the upper boundary of the model, as shown in Figure 5(a). Moreover, Figure 5(b) shows that with the continuous injection of hot solvent vapor, the temperature of the upper part of the injection well in the direction of the well further rose, and the solvent chamber also exhibited horizontal expansion at the top of the model. Under the multiple effects of solvent extraction, temperature, and gravity, the viscosity of heavy oil was greatly reduced, and fluidity was enhanced. The crude oil dissolved in the solvent 
TABLE 2: Injection parameters of 3D experiments.

\begin{tabular}{ccccccc}
\hline No. & Solvent & Injection temperature $\left({ }^{\circ} \mathrm{C}\right)$ & Injection rate $(\mathrm{ml} / \mathrm{min})$ & Permeability $\left(10^{-3} \mu \mathrm{m}^{2}\right)$ & Porosity $(\%)$ & Back pressure $(\mathrm{MPa})$ \\
\hline 1 & n-pentane & 200 & 20 & 12865 & 42.2 & 2 \\
2 & n-pentane & 160 & 20 & 12870 & 41.6 & 1 \\
3 & n-pentane & 150 & 20 & 12888 & 41.5 & 2 \\
\hline
\end{tabular}
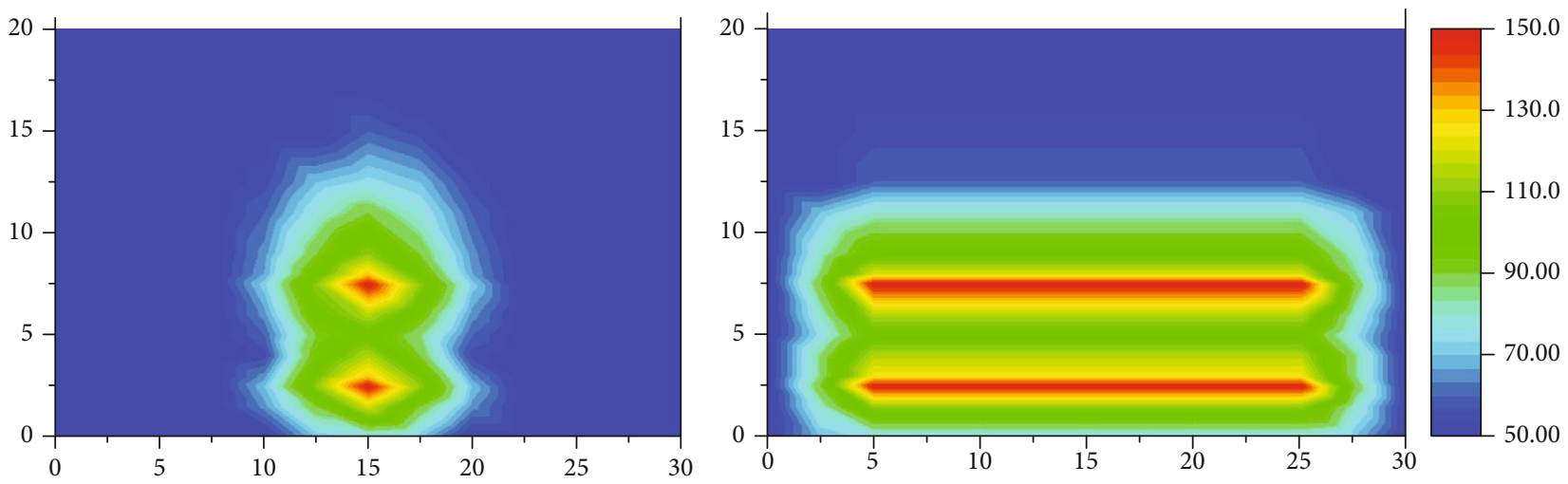

Figure 3: Temperature field in the 3D model at the end of the interwell warm-up stage: (a) in the vertical direction of the wells and (b) along the wells.
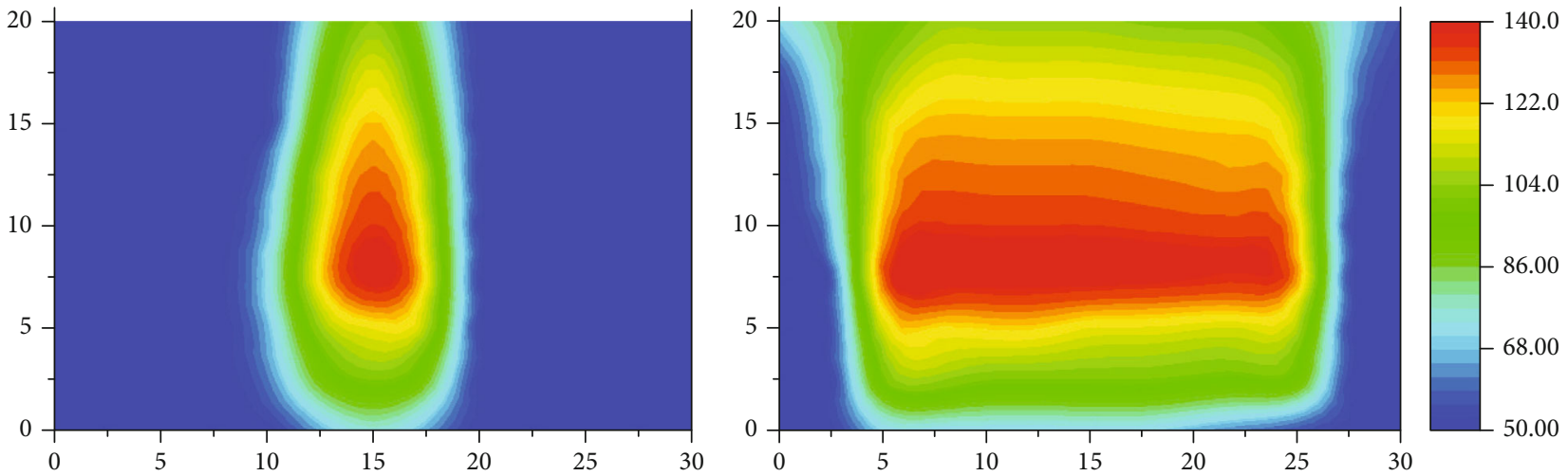

Figure 4: Temperature field in the 3D model during the early stage of Experiment 1: (a) in the vertical direction of the wells and (b) along the wells.
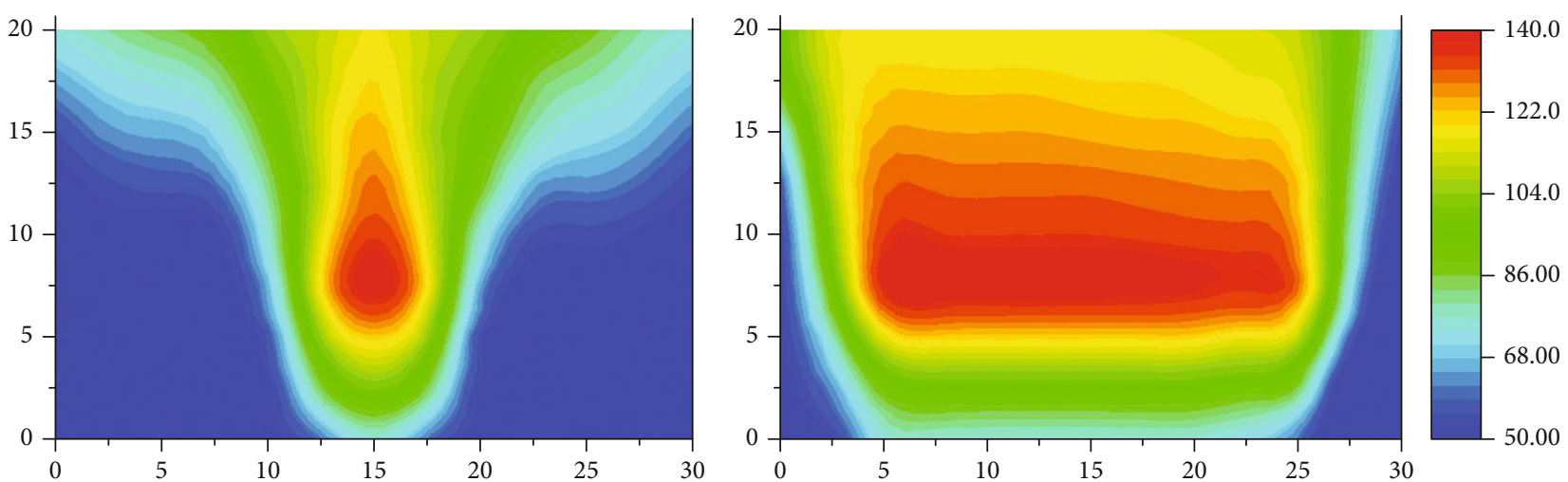

FIgURE 5: Temperature field in the 3D model during the middle stage of Experiment 1: (a) in the vertical direction of the wells and (b) along the wells. 



Figure 6: Temperature field in the 3D model during the end stage of Experiment 1: (a) in the vertical direction of the wells and (b) along the wells.

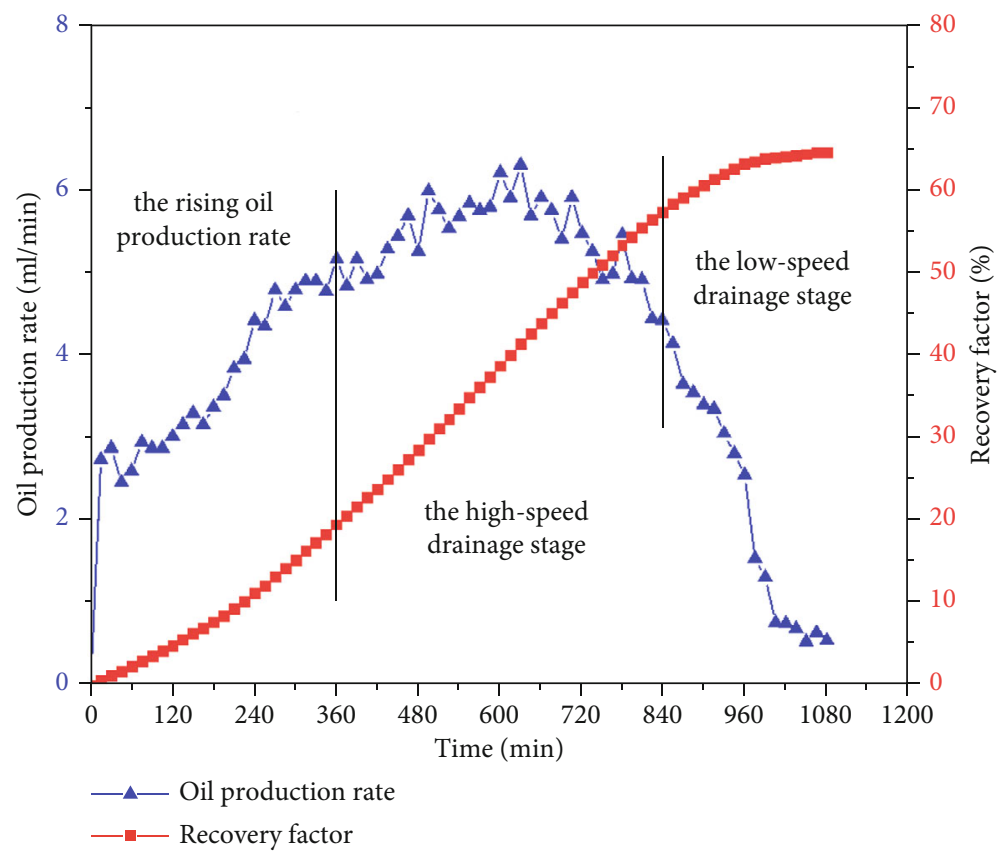

FIGURE 7: Change in the oil production rate and recovery factor with time in Experiment 1.

flowed to the lower part of the model along the interface between the solvent chamber and the crude oil. During this stage involving development of the solvent chamber, the recovery of heavy oil was not large, and the gravity drainage capacity was the strongest.

At the end of production, a large amount of hot solvent was injected, and the diffusion of the hot solvent was enhanced; however, there was considerable heat loss at the top of the model, so the temperature of the solvent chamber rose slowly. As the crude oil in the upper part of the production well was produced in large quantities, the solvent chamber began to expand downward, as shown in Figure 6 . Because $n$-pentane vapor readily diffused and dissolved in crude oil, the solvent diffused to the two corners as the solvent chamber dropped, which increased the solvent chamber range and improved the utilization of crude oil. However, since a large amount of crude oil had been produced, the injected hot solvent was not fully dissolved with the crude oil before it was produced from the production well, resulting in slower development of the solvent chamber and reduction of the movable capacity of the heavy oil.

3.1.2. Production Dynamics. Using the experimentally determined data, the oil production rate curve, cumulative oil exchange rate curve, recovery rate curve, and solvent retention rate of hot solvent mining simulation in Experiment 1 were drawn, as shown in Figures 7 and 8, respectively. Among them, the cumulative oil exchange rate is defined as the ratio of the recovered quality of crude oil to the quality of the solvent remaining in the reservoir, that is, the quality of heavy oil that can be produced by consuming a unit mass of solvent.

Through the analysis of the oil production rate, the hot solvent production process in Experiment 1 was divided into three stages, namely, the rising oil production rate, the highspeed drainage stage, and the low-speed drainage stage. The 


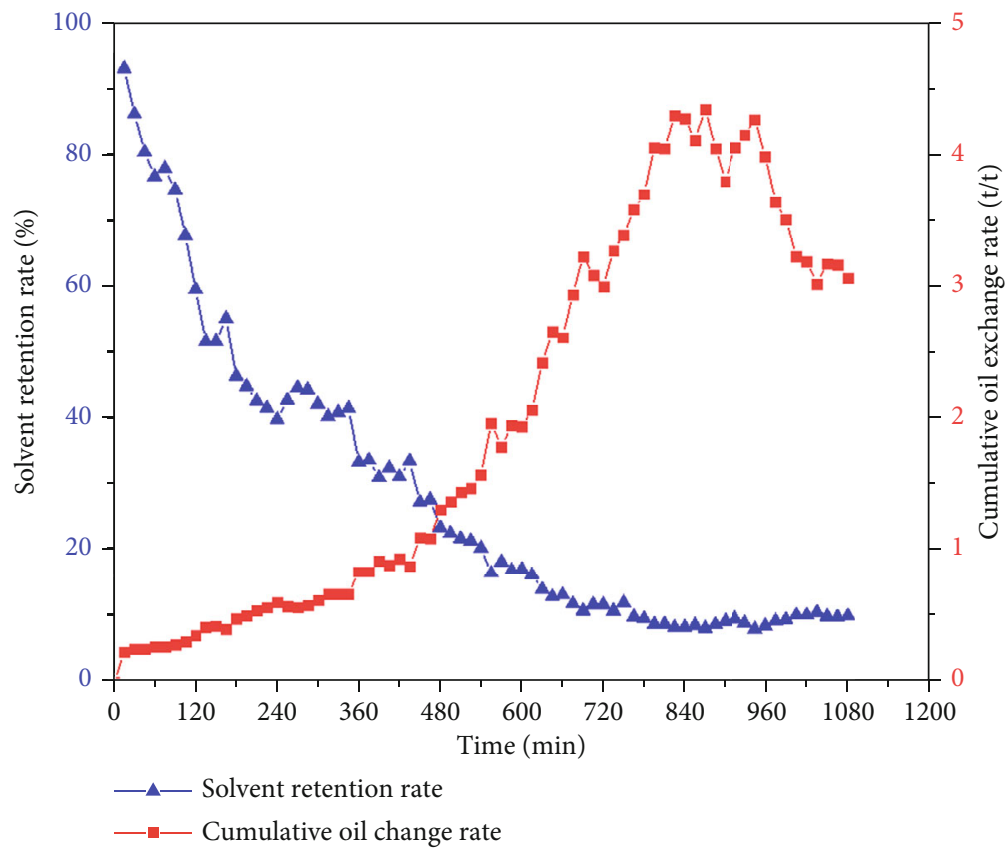

Figure 8: Change in solvent retention efficiency and cumulative oil exchange rate with time in Experiment 1.

cumulative oil production for the entire hot solvent process was $4455.83 \mathrm{ml}$.

From $0 \mathrm{~min}$ to $360 \mathrm{~min}$, the oil production rate rose. In this stage, the oil production rate increased rapidly, reaching $5.2 \mathrm{ml} / \mathrm{min}$. On the one hand, the temperature of the heavy oil between the two wells was increased due to the interwell warm-up stage, which reduced the viscosity of the heavy oil and improved the fluidity of the heavy oil. On the other hand, because the solvent chamber above the production well was not yet developed, the injected solvent diffused. Moreover, part of the solvent burst into the bottom production well so that the crude oil between the injection and production wells was produced from the production well under the action of solvent diffusion and displacement, as shown in Figure 4 . The cumulative oil production increased steadily, and the cumulative oil exchange rate gradually rose to $0.834 \mathrm{t} / \mathrm{t}$. Figure $8 \mathrm{also}$ shows that with the production of crude oil, the injection well was connected to the production well. A part of the solvent may not have been fully diffused and migrated in the model and may have been produced from the production well without being fully dissolved in the crude oil. As a result, the proportion of solvent remaining in the model was greatly reduced to approximately $33.45 \%$. The recovery rate at this stage continued to rise, reaching $19.5 \%$.

The period $360 \mathrm{~min}$ to $840 \mathrm{~min}$ constituted the highspeed drainage stage, and the oil production rate increased continuously. From $480 \mathrm{~min}$, the oil production rate was always maintained at approximately $5.8 \mathrm{ml} / \mathrm{min}$, as shown in Figure 7. The analysis shows that with the continuous injection of hot solvent vapor, the solvent chamber in the model continued to develop, and the contact area with crude oil continued to increase. Furthermore, the hot solvent vapor continuously diffused and dissolved, extracting light hydrocarbon components in the crude oil. In addition, the high- temperature area continued to increase, the viscosity of the crude oil was further reduced by heat, and it continuously flowed along the edge of the solvent chamber to the production well. At this stage, as the process maintained high-speed production, the cumulative oil exchange rate rapidly increased to approximately $4.3 \mathrm{t} / \mathrm{t}$; that is, every injection of 1 unit mass of solvent produced 4.3 units of crude oil, and this remained stable for a period of time. At this time, the solvent retention rate slowly decreased. The analysis indicated that although the total amount of solvent continued to rise with the continuous production of crude oil, the pores in the model required more solvent to fill them, so the decline in solvent retention rate slowed.

From $840 \mathrm{~min}$ to the end, because a large amount of crude oil had been produced, the system was in the lowrate oil production stage. The oil production rate was rapidly reduced to $0.547 \mathrm{ml} / \mathrm{min}$ at $1080 \mathrm{~min}$, and the cumulative oil production increased slowly. The cumulative oil exchange rate at this stage also showed a downward trend, decreasing from a peak of approximately $4.2 \mathrm{t} / \mathrm{t}$ to approximately $3.1 \mathrm{t} / \mathrm{t}$. The solvent chamber continued to expand downward and finally stagnated. At this time, the low oil production rate was low, a large amount of solvent was injected from the production well, the solvent retention rate was relatively stable at approximately $10 \%$, and the final recovery rate was $64.76 \%$.

3.2. Experiment 2. To consider the influence of formation pressure on the hot solvent extraction technology in Experiment 2, the backpressure of the model was set to $1 \mathrm{MPa}$; further, to ensure that the injection pressure was slightly lower than the saturation pressure of the injection temperature, the injection temperature of the hot solvent was set to $160^{\circ} \mathrm{C}$. According to the data from each temperature 

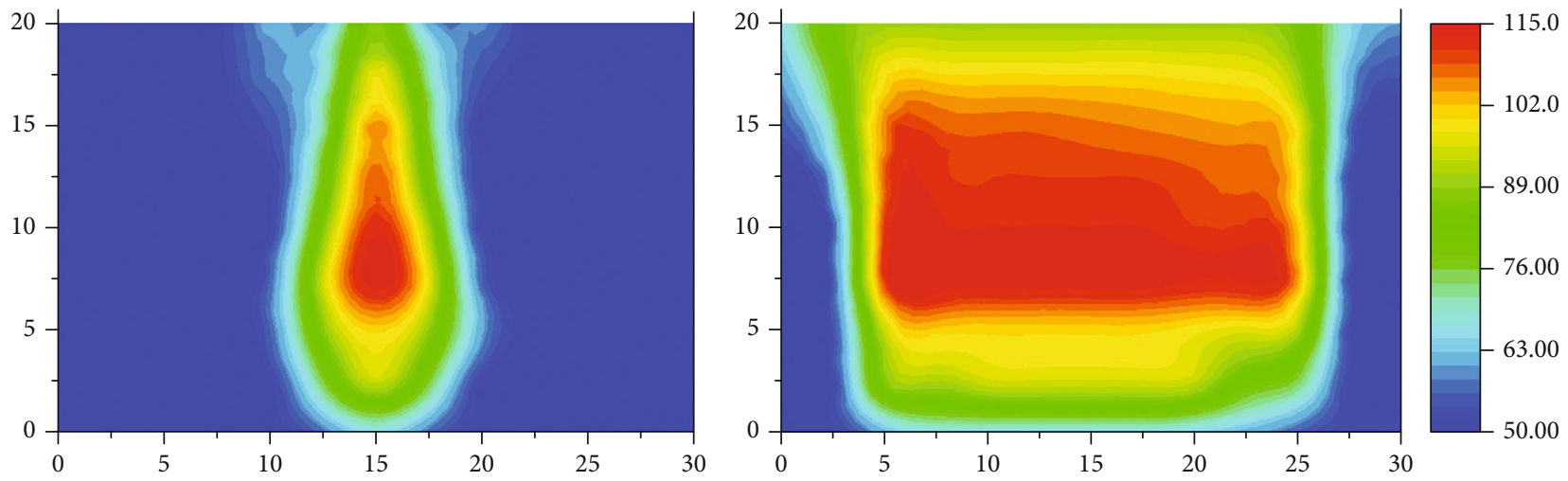

Figure 9: Temperature field in the 3D model during the early stage of Experiment 2: (a) in the vertical direction of the wells and (b) along the wells.
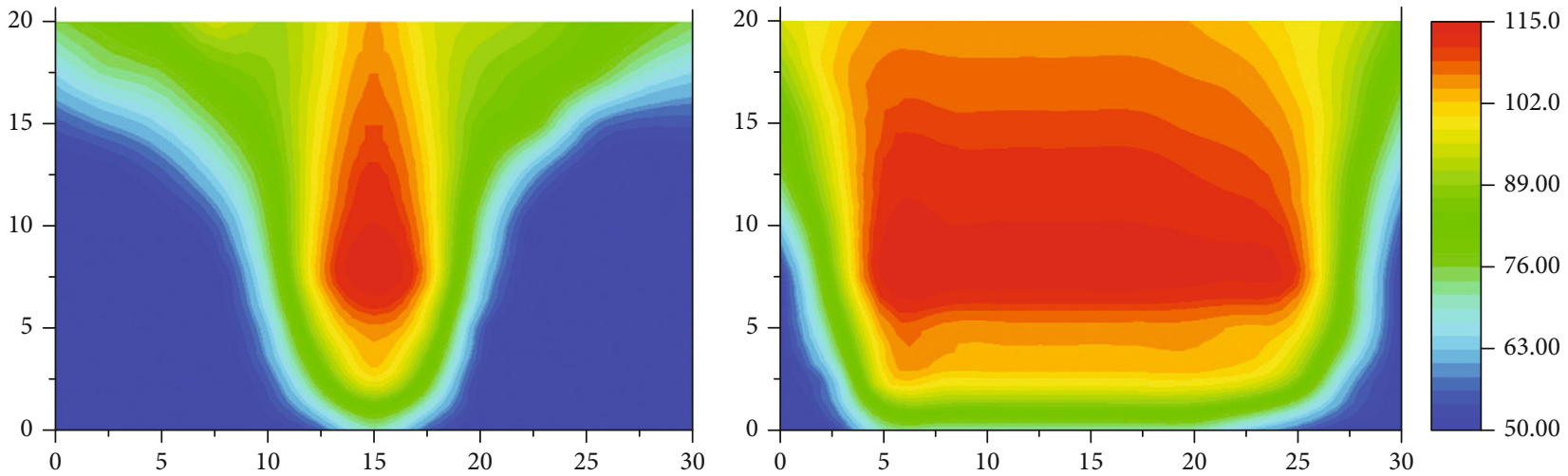

Figure 10: Temperature field in the 3D model during the middle stage of Experiment 2: (a) in the vertical direction of the wells and (b) along the wells.


Figure 11: Temperature field in the 3D model during the end stage of Experiment 2: (a) in the vertical direction of the wells and (b) along the wells.

measurement in the model, the temperature field was developed in the early, middle, and end stages of hot solvent production in Experiment 2.

3.2.1. Solvent Chamber. Figures 9-11 show that the stage of solvent chamber temperature field development in Experiment 2 was basically the same as that in Experiment 1 . The development of the temperature field in the vertical well direction was consistent with the development of the solvent cavity described by Yang Bin [32] and can be divided into the solvent chamber rising phase, lateral expansion phase, and solvent chamber falling phase.

Figure 9 presents the temperature field development diagram at the early stage of hot solvent vapor exploitation at $160^{\circ} \mathrm{C}$. Due to the decrease in the injection temperature, the maximum temperature in the temperature field was 


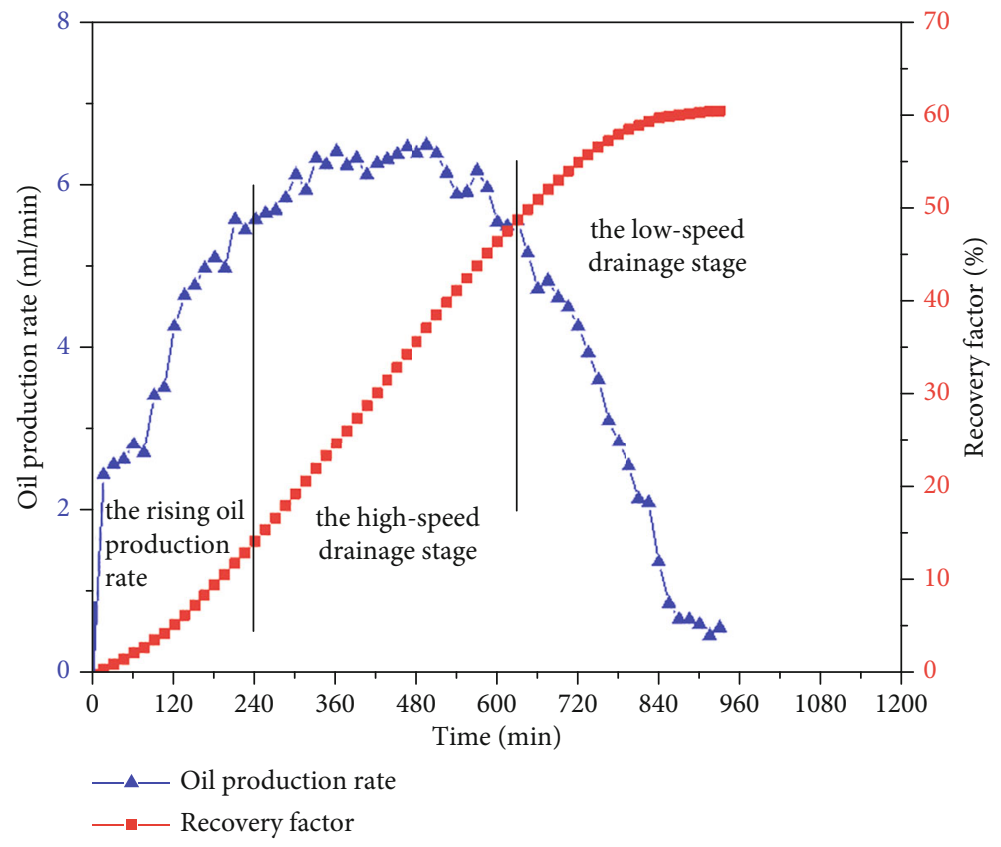

FIGURE 12: Change in the oil production rate and recovery factor with time in Experiment 2.

much lower than that of Experiment 1, and was only approximately $115^{\circ} \mathrm{C}$. However, the main motion state of the hot solvent vapor did not change much. The hot solvent vapor diffused to the top of the model due to gravity differentiation, which caused the temperature field to develop upward. According to the change in the rate of oil production, it can be seen that the lower pressure in the model allowed solvent of the same quality to occupy a larger pore volume, which caused the solvent to spread to the top of the model faster. When the injection well continued to inject hot solvent, the area affected by high temperature gradually increased. It can be seen from Figure 10(a) that the top boundary of the model caused the solvent chamber to gradually develop laterally along the vertical well to extract and heat the crude oil. In the end stage of hot solvent addition, as the crude oil in the upper part of the injection well was produced in large quantities, the solvent chamber began to develop down the boundary.

3.2.2. Production Dynamics. From the experimental data, plots of oil production rate, recovery factor, cumulative oil exchange rate, and solvent retention rate versus production time during the simulation of hot solvent production were drawn, as shown in Figures 12 and 13, respectively.

From the analysis of the experimental data, the cumulative oil production with the hot solvent method in Experiment 2 was determined to be $4154.36 \mathrm{ml}$, and the production process can be divided into three stages as in Experiment 1. From $0 \mathrm{~min}$ to $240 \mathrm{~min}$, the oil production rate rapidly increasing, reaching $5.57 \mathrm{ml} / \mathrm{min}$; oil production rose steadily, and the cumulative oil exchange rate gradually rose to approximately $1 \mathrm{t} / \mathrm{t}$. Then, the system entered the high-speed drainage stage. Starting from $300 \mathrm{~min}$, the oil production rate was maintained at approximately $6.2 \mathrm{ml} /$ min. When the experiment was carried out for $630 \mathrm{~min}$, the cumulative oil exchange rate in this stage increased rapidly to approximately $4 \mathrm{t} / \mathrm{t}$, and the solvent retention rate was in slow decline. From $630 \mathrm{~min}$ to the end of the experiment, the system was in the low-speed drainage stage. The oil production rate was quickly reduced to $0.47 \mathrm{ml} / \mathrm{min}$ at $930 \mathrm{~min}$, and the cumulative oil production rose slowly. The cumulative oil exchange rate at this stage showed an upward trend and then a downward trend, decreasing from a peak of approximately $5.8 \mathrm{t} / \mathrm{t}$ to approximately $4.8 \mathrm{t} / \mathrm{t}$. The development of the solvent chamber began to slow and finally stagnated. At this time, the solvent retention rate was maintained at approximately $6.5 \%$, and the final recovery rate was $60.38 \%$.

3.3. Experiment 3. Considering the influence of the latent heat of solvent condensation on production, this experiment determined that the injected solvent was liquid according to the relationship between the saturation temperature of $n$ pentane and the saturation pressure.

3.3.1. Solvent Chamber. According to the records of various temperature measurements in the $3 \mathrm{D}$ model, the temperature fields of the early, middle, and end stages of the hot solvent production experiment were drawn.

Figures 14-16 show that since the temperature of the injected solvent was relatively low and the solvent was in a liquid state, the amount heat carried by the hot solvent was lower than that in Experiment 2, so the temperature field developed at a lower temperature. Compared to Experiment 2 , the temperature of the temperature field was about $15^{\circ} \mathrm{C}$ lower. However, the development stage and shape of the temperature field were roughly similar to those of Experiments 1 and 2. When the hot solvent was injected, gravity differentiation caused the high-temperature solvent to migrate upward quickly and heat the crude oil injected into 


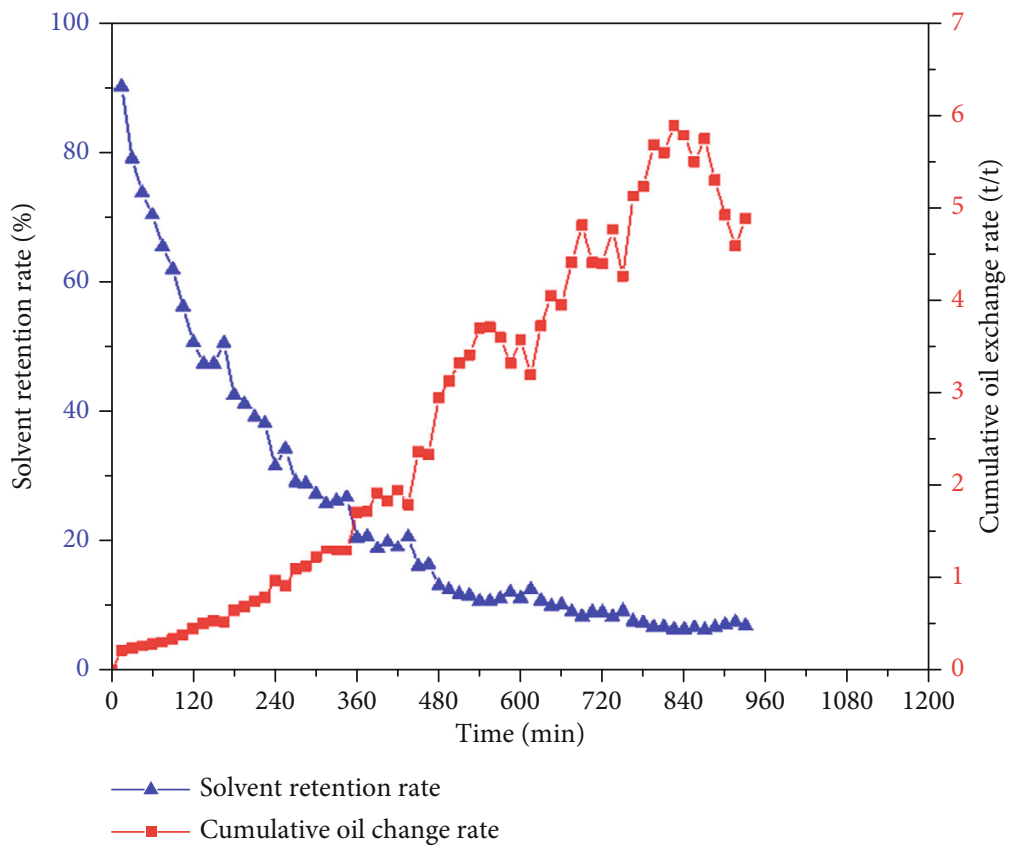

Figure 13: Change in solvent retention rate and cumulative oil exchange rate with time in Experiment 2.
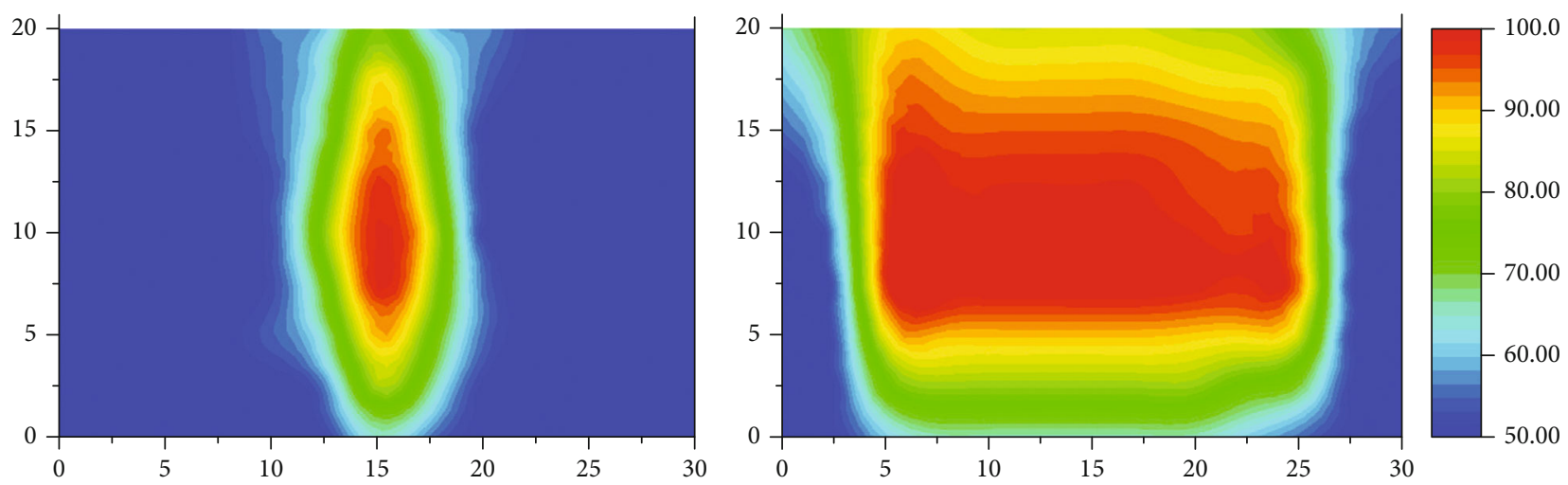

FIGURE 14: Temperature field in the 3D model during the early stage of Experiment 3: (a) in the vertical direction of the wells and (b) along the wells.

the upper end of the well. Due to the influence of seepage resistance, the hot solvent exhibited limited lateral diffusion in the early stage, and the temperature field in the vertical well direction was elongated. As the solvent transferred heat from the toe end to the heel, the temperature field was slightly inclined along the well.

It can be seen from Figure 15(a) that when the hot solvent overlapped the top layer of the model along the vertical direction of the well, it was subjected to gravity differentiation, and the hot solvent gradually began to develop laterally along with the top of the model. The shape of the temperature field is similar to the shape of the solvent chamber that Fang and Babadagli [14] studied under homogeneous conditions. Additionally, the hot solvent heated and dissolved the crude oil on the top of the model and reduced its viscosity, so the crude oil flowed along the interface between the solvent chamber and the crude oil at the output end. In the end stage of hot solvent production, the solvent chamber began to develop toward the lower part of the model. With the continuous production of heavy oil, the degree of crude oil production in the model continued to increase. More liquid solvents were located in the upper part of the production well, which reduced the effect of gravity differentiation. After being injected, a large amount of solvent was located along the interface of the production well without sufficient contact with the crude oil, causing the development of the solvent chamber to stagnate.

3.3.2. Production Dynamics. The relationships of oil production rate and recovery factor with production time is shown in Figure 17, and the plot of solvent retention and cumulative oil exchange rate is shown in Figure 18.

The main production stages of Experiment 3 were consistent with those of the previous two experiments. From $0 \mathrm{~min}$ to $420 \mathrm{~min}$, the oil production rate was increasing, 

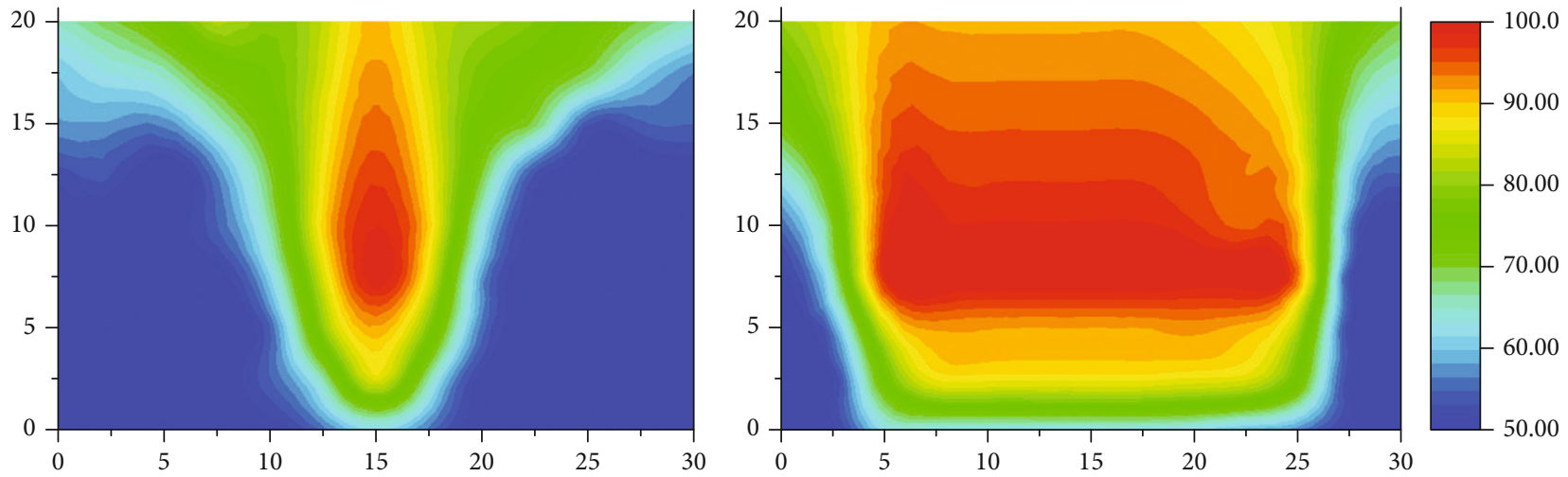

FIGURE 15: Temperature field in the 3D model during the middle stage of Experiment 3: (a) in the vertical direction of the wells and (b) along the wells.
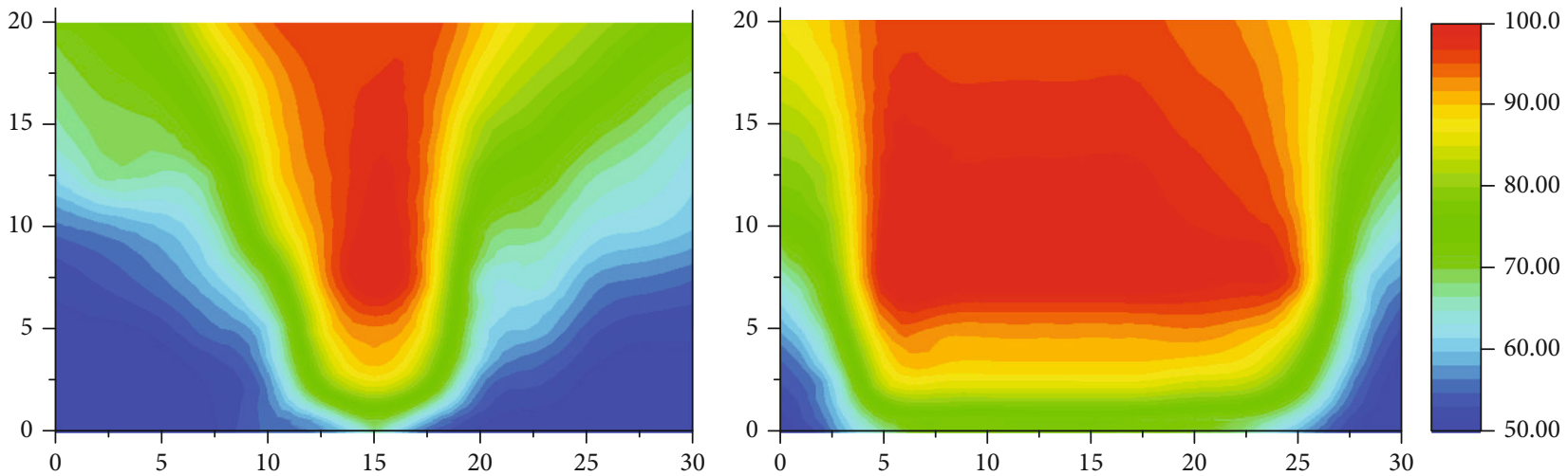

FIGURE 16: Temperature field in the 3D model during the end stage of Experiment 3: (a) in the vertical direction of the wells and (b) along the wells.

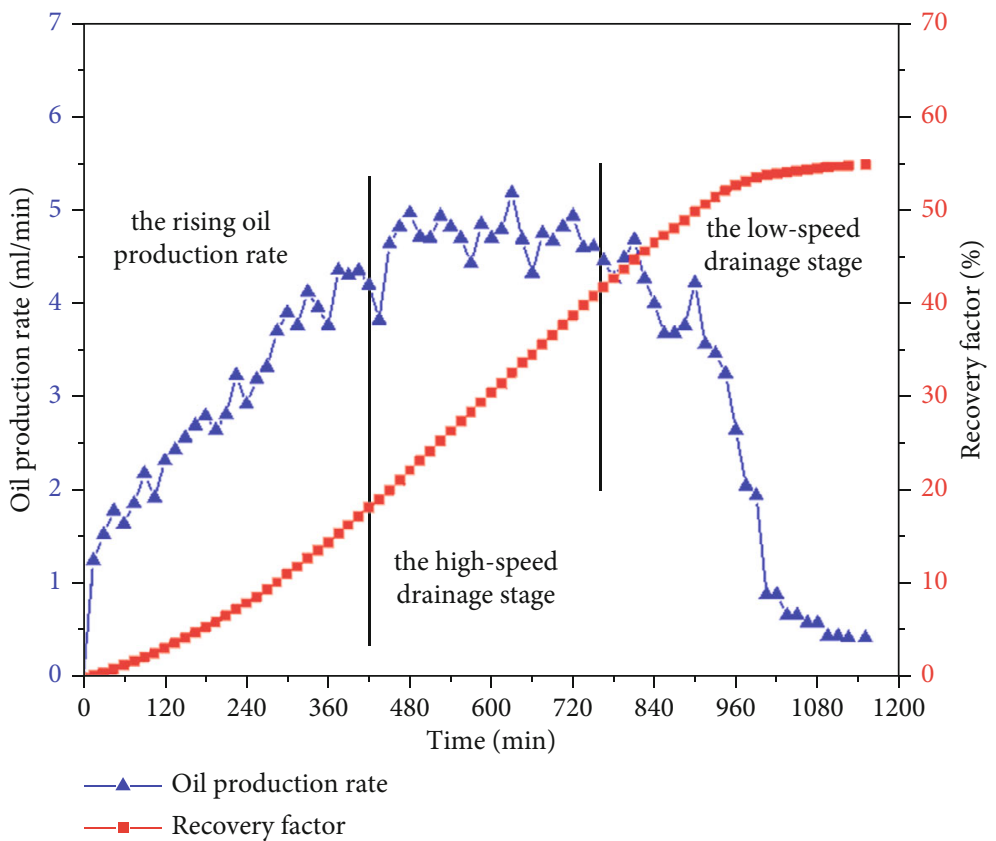

FIGURE 17: Change in the oil production rate and recovery factor with time in Experiment 3. 


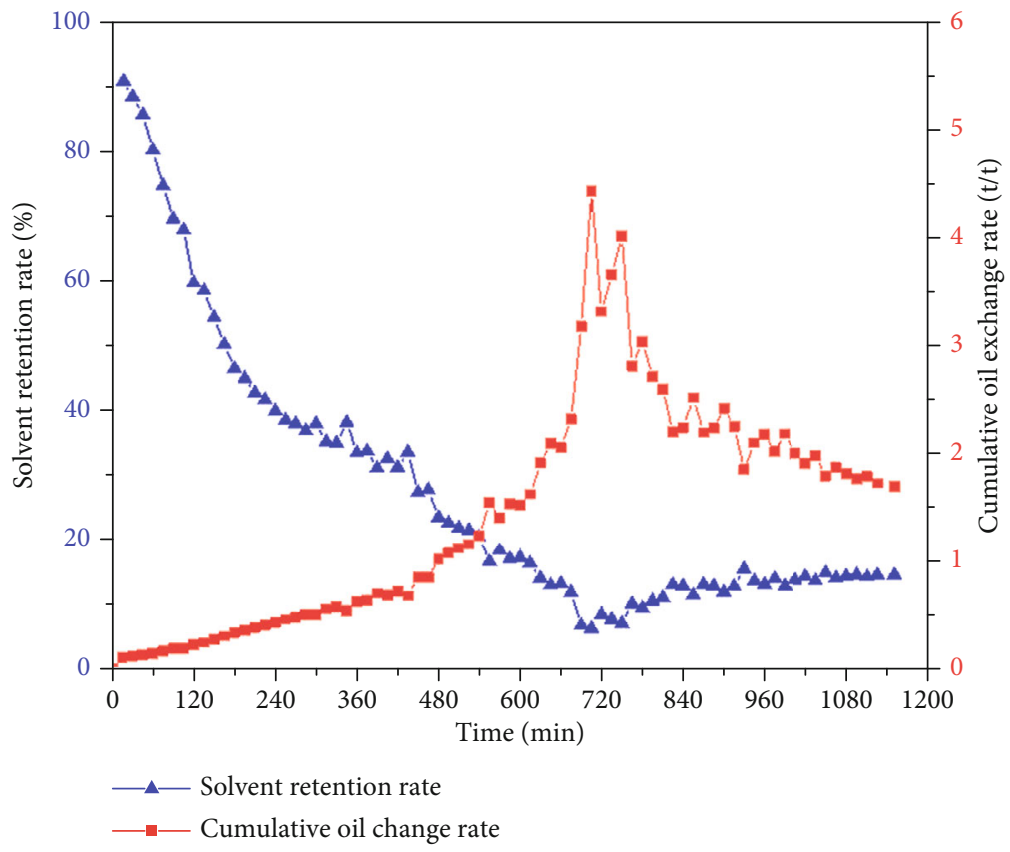

Figure 18: Change in solvent retention rate and cumulative oil exchange rate with time in Experiment 3.

TABLE 3: Results of 3-D physical simulation experiments.

\begin{tabular}{ccccccccc}
\hline No. Experiment & Solvent & $\begin{array}{c}\text { Permeability } \\
\left(\mu \mathrm{m}^{2}\right)\end{array}$ & $\begin{array}{c}\text { Injection } \\
\text { temperature } \\
\left({ }^{\circ} \mathrm{C}\right)\end{array}$ & $\begin{array}{c}\text { Back } \\
\text { pressure } \\
(\mathrm{MPa})\end{array}$ & $\begin{array}{c}\text { Recovery } \\
\text { factor } \\
(\%)\end{array}$ & $\begin{array}{c}\text { Cumulative } \\
\text { oil exchange } \\
\text { rate }(\mathrm{t} / \mathrm{t})\end{array}$ & $\begin{array}{c}\text { Solvent } \\
\text { retention } \\
\text { rate }(\%)\end{array}$ \\
\hline 1 & 1 & n-pentane & 12.87 & 200 & 2 & 64.76 & 3.1 & 10.0 \\
2 & 2 & n-pentane & 12.87 & 160 & 1 & 60.38 & 4.8 & 1.6 \\
3 & 3 & n-pentane & 12.89 & 150 & 2 & 54.79 & 1 & 1 \\
4 & & propane & 250 & 22 & 0.758 & 31 & $/$ & $/$ \\
5 & Parnian & propane & 250 & 50 & 0.758 & 60.86 & $/$ & $/$ \\
6 & Haghighat & propane & 250 & 50 & 1.46 & 87.54 & $/$ \\
\hline
\end{tabular}

and it gradually rose to $4.63 \mathrm{ml} / \mathrm{min}$. Oil production rose steadily, and the cumulative oil exchange rate gradually increased to approximately $0.83 \mathrm{t} / \mathrm{t}$. Since the injected solvent was liquid, the heat content was lower than those of the solvent vapor used in the previous two experiments, so the startup time for high-speed production was extended. From $420 \mathrm{~min}$ to $760 \mathrm{~min}$, system was in the stage of highspeed drainage, and the oil production rate was maintained at approximately $4.8 \mathrm{ml} / \mathrm{min}$. In this stage, the cumulative oil exchange rate rapidly increased to approximately $3.3 \mathrm{t} / \mathrm{t}$, the solvent retention rate was in decline, and the cumulative oil production increased rapidly.

From $760 \mathrm{~min}$ to the end, the system entered the lowspeed drainage stage. The oil production rate was rapidly reduced to $0.43 \mathrm{ml} / \mathrm{min}$ at $1150 \mathrm{~min}$, and the cumulative oil production rose slowly. The cumulative oil exchange rate at this stage dropped rapidly, from a peak of approximately $4 \mathrm{t} / \mathrm{t}$ to approximately $1.6 \mathrm{t} / \mathrm{t}$. The development of the solvent chamber began to slow and finally stagnated. At this time, the solvent retention rate was relatively stable at approximately $14.5 \%$. The final cumulative oil production of this experiment was $3739.34 \mathrm{ml}$, and the final recovery factor was $54.79 \%$.

3.4. Comparative Analysis. To aid studying the influence of pressure and temperature on hot solvent production technology, a comparison of the results of the three sets of experiments is shown in Table 3. The highest recovery factor of Experiment 1 was $64.76 \%$, and the cumulative oil exchange rate was $3.1 \mathrm{t} / \mathrm{t}$. In Experiment 2, the highest cumulative oil exchange rate was $4.8 \mathrm{t} / \mathrm{t}$, and the solvent retention rate was the lowest at only $6.5 \%$. Experiment 3 has the lowest recovery rate and cumulative oil exchange rate, which were only $54.79 \%$ and $1.6 \mathrm{t} / \mathrm{t}$, respectively, and the solvent retention rate was the highest, at $14.5 \%$. As with the experimental results of Haghighat and Maini [28], our data showed that the recovery of solvents increased with increasing temperature.

As shown by comparing data for Experiment 1 and Experiment 2, with decreasing pressure and temperature, the oil recovery decreased by $4.38 \%$. However, the cumulative oil exchange rate increased from $3.1 \mathrm{t} / \mathrm{t}$ to $4.8 \mathrm{t} / \mathrm{t}$, and 
the solvent retention rate in the model also decreased from $10 \%$ to $6.5 \%$. Although the cumulative oil production in Experiment 2 was lower, the relative economic benefits were greatest. According to the analysis, both Experiment 1 and Experiment 2 had hot solvent vapor injected, and hot vapor has considerable ability to reduce viscosity through dissolution. The temperature of the hot solvent injected in Experiment 2 was lower than that in Experiment 1, making the temperature for development of the temperature field lower. Crude oil had a slightly poorer viscosity reduction when heated, and its flow resistance was relatively large, which made the recovery factor slightly lower. However, due to the low pressure used in the model, the mass of hot solvent contained in the same pore volume was reduced, so the solvent retention rate in the model was reduced, and the cumulative oil exchange rate was increased.

Since the temperatures of Experiment 2 and Experiment 3 were close, they were regarded as the same temperature to study the influence of pressure on the hot solvent mining technology. By comparing the results of Experiment 2 and Experiment 3, it was found that the recovery factor of Experiment 2 was $5.59 \%$ higher than that of Experiment 3, the cumulative oil exchange rate was three times that of Experiment 3, and the solvent retention rate was far lower than that of Experiment 3. The analysis suggests that although the injection temperatures of the hot solvents were the same, the injected n-pentane was liquid due to the higher model pressure used in Experiment 3. The heat carried by a liquid solvent is lower than that of solvent in the vapor state, so the temperature for development of the temperature field was lower than in Experiment 2, the viscosity of crude oil was higher than in Experiment 2. Meanwhile, as reservoir (rock formation) pressure increased, the throats inside the rock would become narrow, which decreased the mobility of the fluid and increased its retention inside the reservoir. Solvent vapor had greater kinetic energy than liquids, and the diffusion capacity of vapor was enhanced in the model. Vapors can better contact and dissolve the crude oil and they exhibited full use of the solvent's capacity for dissolving and reducing viscosity, so Experiment 2 provided a higher recovery factor. In addition, for solvent vapor, the same pore volume only needs to be filled with a smaller quality solvent, so Experiment 2 had a smaller solvent retention rate and a larger cumulative oil exchange rate while producing more crude oil. However, the recovery of the solvent increased with increasing experimental pressure, according to literature reports. This is because the solvents injected in the literature were still gaseous solvents. In this paper, with increasing pressure, the solvent became liquid, which reduced the effect of the solvent in the oil displacement model. Therefore, solvent should be primarily injected as vapor.

Through comparison of the results of Experiment 1 and Experiment 3, it was found that the recovery factor was reduced from $64.76 \%$ to $54.79 \%$. This result is consistent with the experimental result of Haghighat and Maini. When the pressure was constant, the recovery factor decreased with decreasing temperature. Furthermore, the cumulative oil exchange rate was reduced from $3.1 \mathrm{t} / \mathrm{t}$ to $1.6 \mathrm{t} / \mathrm{t}$, and the solvent retention rate was increased by $4.5 \%$. The analysis suggests that when the injection pressure was constant, the temperature of the injected hot solvent was lowered, and the phase of the hot solvent changed from a gaseous state to a liquid state, which reduced the amount of heat carried by the solvent. According to the data on the temperature field, the temperature in the temperature field of Experiment 3 was relatively low. Although the solubility was increased, the kinetic energy of the hot solvent decreased, and the diffusion capacity in the model diminished, which led to a decrease in the production of crude oil. In addition, the effect of heating the crude oil to reduce viscosity worsened, and the recovery factor was greatly reduced. Finally, because the same pore volume was filled with more quality solvents, not only were the recovery factor and the cumulative oil production reduced, but the solvent content in the model increased, and the cumulative oil exchange rate decreased.

\section{Conclusion}

(1) In the heat injection solvent production experiment, regardless of whether the solvent is injected in liquid or steam, the development of the solvent chamber can be divided into three stages: rapid rise phase, horizontal expansion phase, and slow decline phase. In addition, the solvent vapor carries more heat, which further reduces the viscosity of the heavy oil and improves the fluidity of the heavy oil

(2) For constant temperature, the lower the reservoir pressure is, the higher the recovery rate, the greater the cumulative oil exchange rate, the lower the solvent retention rate, and the greater the economic benefit. When the reservoir pressure is constant, the higher the temperature is, the higher the oil recovery rate, the greater the cumulative oil exchange rate, the lower the solvent retention rate, and the greater the economic benefit. As reservoir (rock formation) pressure increases, the throats inside the rock will become narrow, which decreases the mobility of the fluid and increases its retention inside the reservoir

(3) Through three-dimensional experiments, it is found that compared with injecting liquid hot solvent, the volume of hot solvent vapor injected is less and the oil production rate is higher. The solvent retention rate is not more than $10 \%$, the cumulative oil exchange rate is more than $3 \mathrm{t} / \mathrm{t}$, and the recovery rate is more than $60 \%$, which results in greater economic benefit

\section{Data Availability}

The data used to support the findings of this study are included within the article.

\section{Conflicts of Interest}

The authors declare that they have no conflicts of interest. 


\section{Acknowledgments}

This project was financially supported by the National Natural Science Foundation of China (No. 51774306 and No. U20B6003), National Key Scientific and Technological Project for the Oil \& Gas Field and Coalbed Methane of China (2016ZX05031002-004-002), and the Youth Innovation of University in Shandong Province under (No. 2019KJH002). We are grateful to the Shandong Engineering Research Center for Foam Application in Oil and Gas Field Development and UPC-COSL Joint Laboratory on Heavy Oil Recovery for their assistance with the experimental research.

\section{References}

[1] T. Babadagli, "Technology focus: heavy oil," Journal of Petroleum Technology, vol. 71, no. 4, pp. 68-68, 2019.

[2] S. Li, Q. Wang, and Z. Li, "Stability and flow properties of oilbased foam generated by $\mathrm{CO}_{2}$," SPE Journal, vol. 25 , no. 1 , pp. 416-431, 2020.

[3] S. Li, Z. Hu, W. M. Lu Cn, K. Zhang, and W. Zheng, "Microscopic visualization of greenhouse-gases induced foamy emulsions in recovering unconventional petroleum fluids with viscosity additives," Chemical Engineering Journal, vol. 411, article 128411, 2021.

[4] Z. Xu, Z. Li, A. Jing, F. Meng, F. Dang, and T. Lu, "Synthesis of magnetic graphene oxide (MGO) and auxiliary microwaves to enhance oil recovery," Energy \& Fuels, vol. 33, no. 10, pp. 9585-9595, 2019.

[5] R. M. Butler and D. J. Stephens, "The gravity drainage of steam-heated heavy oil to parallel horizontal wells," Journal of Canadian Petroleum Technology, vol. 20, no. 2, p. 8, 1981.

[6] S. Li, T. Yu, Z. Li, and K. Zhang, "Experimental investigation of nitrogen-assisted SAGD in heavy-oil reservoirs: a twodimensional visual analysis," Fuel, vol. 257, pp. 1-16, 2019.

[7] H. Hashemi-Kiasari, A. Hemmati-Sarapardeh, S. Mighani, A. H. Mohammadi, and B. Sedaee-Sola, "Effect of operational parameters on SAGD performance in a dip heterogeneous fractured reservoir,” Fuel, vol. 122, pp. 82-93, 2014.

[8] C. Zou, H. Xue, B. Xiong et al., "Connotation, innovation and vision of "Carbon neutrality"," Natural Gas Industry B, vol. 8, no. 5, pp. 523-537, 2021.

[9] S. Li, R. Han, P. Wang, Z. Cao, Z. Li, and G. Ren, "Experimental investigation of innovative superheated vapor extraction technique in heavy oil reservoirs: a two-dimensional visual analysis," Energy, vol. 238, article 121882, 2022.

[10] R. M. Butler and I. J. Mokrys, "A new process (VAPEX) for recovering heavy oils using hot water and hydrocarbon vapour," Journal of Canadian Petroleum Technology, vol. 30, no. 1, pp. 97-106, 1991.

[11] S. K. Das and R. M. Butler, "Mechanism of the vapor extraction process for heavy oil and bitumen," Journal of Petroleum Science and Engineering, vol. 21, no. 1-2, pp. 43-59, 1998.

[12] S. K. Das and R. M. Butler, Extraction of Heavy Oil and Bitumen Using Solvents at Reservoir Pressure. Technical meeting/ petroleum conference of the South Saskatchewan section, Petroleum Society of Canada, 1995.

[13] R. M. Butler and Q. Jiang, "Improved recovery of heavy oil by VAPEX with widely spaced horizontal injectors and pro- ducers," Journal of Canadian Petroleum Technology, vol. 39, no. 1, pp. 8-56, 2000.

[14] F. Fang and T. Babadagli, "Three dimensional visualization of solvent chamber growth during the VAPEX processes: an experimental approach using laser," Journal of Petroleum Science and Engineering, vol. 142, pp. 46-67, 2016.

[15] B. Yang, H. Jiang, and G. U. Yonggan, "Experiment on injection pressure of vapor extraction process," Journal of China University of Petroleum, vol. 33, no. 6, pp. 77-81, 2009.

[16] Q. Jiang and R. M. Butler, "Experimental studies on effects of reservoir heterogeneity on VAPEX process," Journal of Canadian Petroleum Technology, vol. 35, no. 10, pp. 46-54, 1996.

[17] N. Rezaei, O. Mohammadzadeh, and L. A. James, "Experimental investigation of the VAPEX process in vuggy porous media," SPE Journal, vol. 19, no. 1, pp. 101-108, 2014.

[18] B. Rostami and R. Azin, "Investigation of the VAPEX process in high pressure fractured heavy oil reservoirs," in SPE International Thermal Operations and Heavy Oil Symposium, Calgary, Alberta, Canada, 2005.

[19] Y. Li, Y. Wu, and F. Zhao, "Influence factors experiment of deasphalting in solvent vapor extraction," Acta Petrolei Sinica, vol. 35, no. 5, pp. 935-940, 2014.

[20] M. M. Al-Hadhrami, S. Abdullah, A. H. Alkindi, and Muggeridge, "Experimental and numerical investigations into the effect of heterogeneities on the recovery of heavy oil by vapour extraction (VAPEX)," Fuel, vol. 135, pp. 413-426, 2014.

[21] T. Jiang, F. Zeng, X. Jia, and Y. Gu, "A new solvent-based enhanced heavy oil recovery method: cyclic production with continuous solvent injection," Fuel, vol. 115, pp. 426-433, 2014.

[22] K. Zhang and X. Zhou, "A comparison study between N-Solv method and cyclic hot solvent injection (CHSI) method," Journal of Petroleum Science and Engineering, vol. 173, pp. 258268, 2019.

[23] A. Daryasafar and K. Shahbazi, "The effect of different solvents on the density of undersaturated Athabasca bitumen: application in VAPEX and ES-SAGD," Petroleum Science and Technology, vol. 3, pp. 222-226, 2018.

[24] S. Li, L. Wang, L. Su, Z. Li, and K. Zhang, "Carbon dioxide diffusions in methane-dissolved pore fluids: implications for geological carbon storage and utilization in tight formations," Chemical Engineering Journal, vol. 429, article 132147, 2022.

[25] J. E. Nenniger and S. G. Dunn, "How fast is solvent based gravity drainage," in The 59th Canadian International Petroleum Conference, Calgary, Alberta, June 2008.

[26] E. Nenniger and J. Nenniger, Method and apparatus for stimulating heavy oil product, N-Solv Corp, 2005, US Patent 20050145383A1.

[27] L. A. James, Mass Transfer Mechanisms during the Solvent Recovery of Heavy Oil, The University of Waterloo, ON, Canada, 2009.

[28] P. Haghighat and B. B. Maini, "Experimental evaluation of heated VAPEX process," in SPE Heavy Oil Conference Canada 2012, Calgary, Alberta, Canada, 2012.

[29] N. Rezaei, Experimental Investigations in Improving the VAPEX Performance for Recovery of Heavy Oil and Bitumen, University of Waterloo, 2010.

[30] N. Rezaei, O. Mohammadzadeh, and I. Chatzis, "Warm VAPEX: a thermally improved vapor extraction process for 
recovery of heavy oil and bitumen," Energy \& Fuels, vol. 24, pp. 5934-5946, 2010.

[31] T. W. Frauenfeld, X. Deng, and C. Jossy, "Economic analysis of thermal solvent processes," in The Petroleum Society's 7th Canadian International Petroleum Conference (57th Annual Technical Meeting), Calgary, AB, June 2006.

[32] B. Yang, Y. Fang, and G. Wang, "Indoor test of heavy oil recovery by gravity drainage with solvent," Petroleum Drilling Techniques, vol. 40, no. 3, pp. 102-106, 2012. 